\title{
The influence of dietary conjugated linoleic acid isomers and selenized yeast on the fatty acid profile of the spleen, pancreas and kidneys of rats
}

\author{
K. Korniluk, M. Czauderna ${ }^{1}$ and J. Kowalczyk \\ The Kielanowski Institute of Animal Physiology and Nutrition, \\ Polish Academy of Sciences \\ 05-110 Jabłonna, Poland
}

(Received 10 November 2006; accepted 2 February 2007)

\begin{abstract}
The influence of $1.2 \mathrm{ppm}$ dietary selenium added in the form of selenized yeast (Se-yeast) and of a mixture of conjugated linoleic acid (CLA) isomers added to a level of 1 or $2 \%$, of cis 9 trans 11CLA (c9t11) added to $1 \%$, and of trans10cis 12CLA ( $110 c 12)$ added to $1 \%$ on the body and organ gains of rats and on the concentration of CLA isomers and other fatty acids in the spleen, pancreas and kidneys was investigated. Total fatty acids in the studied organs were separated as methyl esters using long-capillary gas-liquid chromatography with flame-ionization detection, while nonmethylated fatty acids containing conjugated double bonds were examined using silver-ion liquid chromatography with fotodiode detection. Free fatty acids were obtained by mild saponification, whereas their methyl esters, by base- and acid-catalyzed methylation. Feeding $t 10 c 12$ and Se-yeast resulted in the highest increase in rat growth and organ gain. All diets enriched in CLA isomer(s) significantly elevated the concentration of CLA isomers in the organs; the highest concentration of CLA isomers was found in the pancreas, the smallest, in the spleen. The addition of Se to diets containing CLA isomer(s) usually showed a statistical tendency or increase in the concentration of CLA isomers in the organs. Our results demonstrate that $t 10 c 12$ was metabolized faster than c9t11 in the pancreas and kidneys, whereas the addition of Se-yeast to the diets with CLA isomer(s) reduced the rate of $t 10 \mathrm{c} 12$ metabolism. A $2 \%$ dietary content of a mixture of CLA isomers or of t10c12 usually tended to increase or significantly increased the concentration of linoleic, linolenic, and arachidonic acids and of n-3 long-chain polyunsaturated fatty acids (n-3 PUFA) in the organs. Dietary $c 9 t 11$ and a $1 \%$ content of the mixture of CLA isomers weakly influenced the concentrations of these fatty acids in the organs, whereas the diet enriched simultaneously in $c 9 t 11$ and Se-yeast resulted in a statistical tendency or increase in the concentration of long-chain n-3 PUFA and the
\end{abstract}

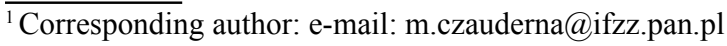


sum of PUFA in the organs compared with the control group and rats fed the diet containing only c9t11. The obtained results suggest that $t 10 c 12$ and, in particular, $2 \%$ of the mixture of CLA isomers decreased the capacities of $\Delta 9-, \Delta 6-, \Delta 5$ - and $\Delta 4$-desaturases, as well as of cyclooxygenase-1, and/or the inducible form, cyclooxygenase-2, at the level of mRNA, protein, or activity.

KEY WORDS: CLA isomers, high-selenized yeast, fatty acids, spleen, pancreas, kidneys, rats

\section{INTRODUCTION}

The term conjugated linoleic acid(CLA) isomers refers to a collection of positional and geometric isomers of octadecadienoic acid with conjugated double bonds. The recent increased interest in CLA isomers results from numerous animal investigations associating conjugated fatty acids, particularly cis9trans 11CLA (c9t11), with healthpromoting effects (Belury, 2002; Naumanna etal., 2006). Furthermore, trace elements, including selenium (Se), are also crucial nutrients for humans as well as all animals. Se is a component of a number of important selenoproteins and enzymes required for such functions as antioxidant and anticancer defence, reduction of inflammation, thyroid hormone production, DNA synthesis, fertility and reproduction (Kornitzer et al., 2004; Rayman, 2004). Consequently, adequate dietary intake of CLA isomers and $\mathrm{Se}$ is essential for good health. Interestingly, numerous animal investigations found that the contents of mono- (MUFA) and polyunsaturated fatty acids (PUFA), especially in serum cholesterol esters and phospholipids, were positively correlated with Se concentrations in the diet (Crespo et al., 1995). According to Tapiero et al. (2003) and Suzuki (2005), half of known Se-proteins have been implicated in antioxidant functions, and Se-cysteine (Se-Cys) is essential in the active centres of Se-enzymes that carry out redox reactions, e.g., glutathione peroxidase (GPx), thyroid hormone deiodinase families, or thioredoxin reductase (Tapiero et al., 2003). Phospholipid hydroperoxide cGPx in particular interacted more directly than cytosolic and mitochondrial cGPx in protecting PUFA from peroxidation damage (Crespo et al., 1995). Recent investigations have shown that feeding diets enriched in high-selenized yeast (Se-yeast; 83-60\% Se as Se-methionine (Se-Met) (Rayman, 2004)) to animals results in effective induction of antioxidant enzymes, indicating that the animal converts this chemical form of Se-Met to Se-Cys, which is an essential amino acid for the synthesis of this Se-protein (Schomburga et al., 2004; Whanger, 2004; Korniluk et al., 2006). Thus, these protective effects of dietary Se (as high-selenized yeast) on the deposition of CLA isomers and other fatty acids in the body of mammals may also be plausible.

In recent studies we found that dietary $\mathrm{Se}$ (as high-selenized yeast and selenate) and CLA isomers influence the amount of CLA isomers and other fatty acids in 
the liver and femoral muscles of rats (Czauderna et al., 2004a,b; Korniluk et al., 2006). Considering the above, we hypothesized that addition of high-selenized yeast (Se-yeast) to rats' diets containing CLA isomers caused changes in the yield of the accumulation of CLA isomers and other fatty acids in the examined organs of rats. Therefore, the objective of the present study was to investigate the effect of adding Se-yeast to diets enriched to 1 or $2 \%$ of a mixture of CLA isomers or to $1 \%$ of individual CLA isomers (i.e. $c 9 t 11$ and $t 10 c 12$ ) on the concentration of fatty acids, particularly CLA isomers, in the spleen, pancreas, and kidneys of rats. Moreover, the influence of the experimental factors on the body weight gain of rats, the weight of these organs and feed intake was also determined.

\section{MATERIAL AND METHODS}

\section{Animals and treatments}

Ten groups of 8-week-old female rats (Wistar, Ifz: BOA) were housed individually in plastic cages as described by Korniluk et al. (2006). The animals were housed and handled in accordance with protocols approved by the Local Animal Care and Use Committee (The Agricultural University of Warsaw, Poland). During a one-week preliminary period the animals were fed a standard Labofeed H diet (Pastuszewska et al., 2000) given at a submaintenance level ( $\sim 9 \mathrm{~g}$ of the diet per rat daily) to reduce their body fat. In the experimental period lasting 4 weeks, the rats were fed ad libitum with the Labofeed $\mathrm{H}$ diet enriched to 1 or $2 \%$ of a mixture of CLA isomers, 1\% cis 9 trans 11 CLA (c9t11), 1\% trans10cis12CLA (t10c12) and/or $1.2 \mathrm{ppm} \mathrm{Se}$, as Se-yeast (Rayman, 2004). After 28 days of feeding the experimental diets the rats were euthanized by $\mathrm{CO}_{2}$ and the spleen, pancreas and kidneys were removed, weighed, and analysed for their fatty acids.

\section{Chemicals}

Water and organic solvents were HPLC grade, whereas all of the remaining reagents were analytical grade. The CLA isomer mixture, individual CLA isomers (i.e. $c 9 t 11$ and $t 10 c 12$ ) were supplied by Larodan Fine Chemicals AB (Sweden). The purity and composition of the CLA isomer mixture and individual isomers were examined by $\mathrm{Ag}^{+}$-HPLC and GLC (Table 1) (Czauderna et al., 2003a, 2005). All fatty acid standards were provided by Sigma (USA), while n-heptane (95\%) was purchased from Lab-Scan (Ireland). A non-commercial Se-yeast sample was donated by Sel-Plex, Alltech Inc. (USA). The compositions of the Labofeed H diet and dietary Se-yeast sample are presented in Table 2. 


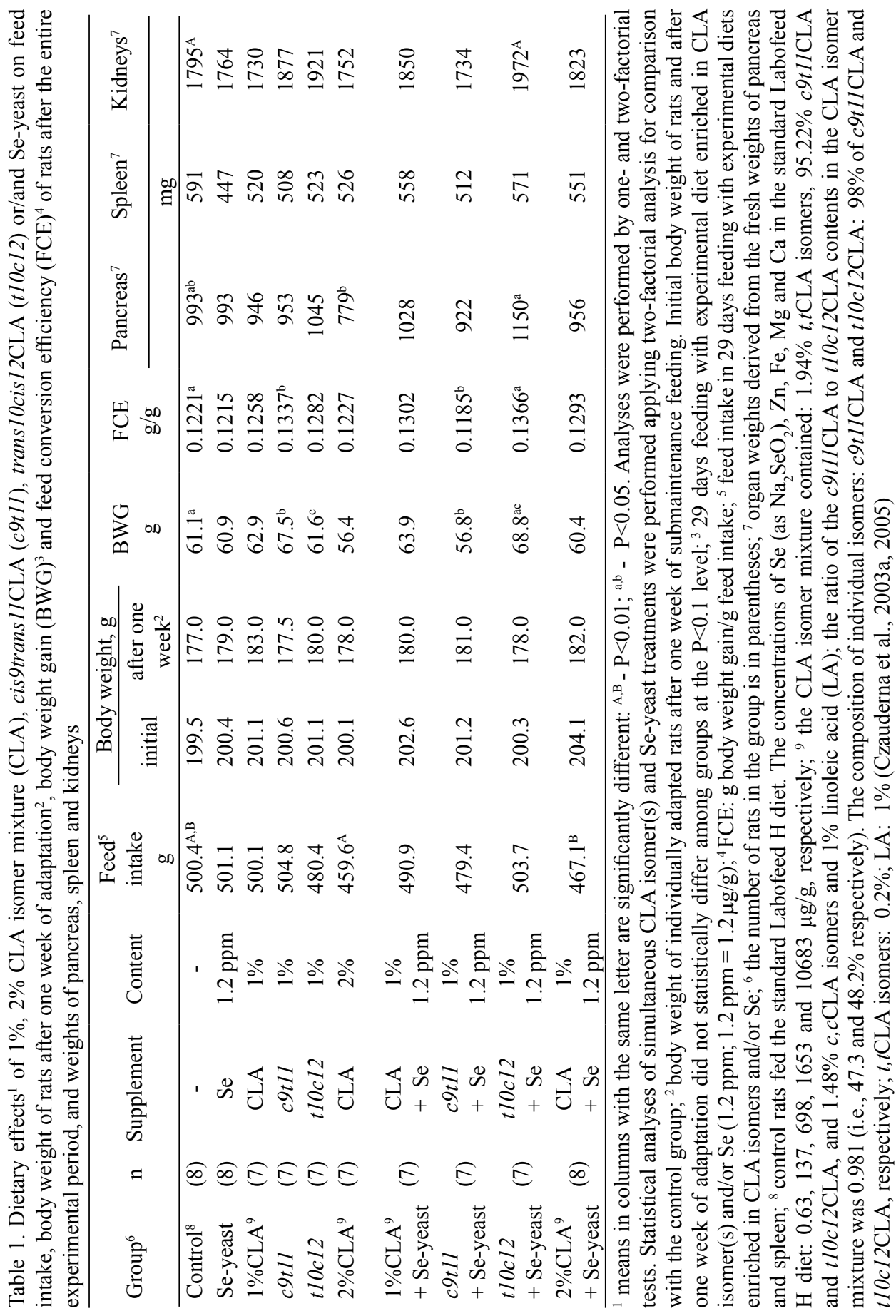


Table 2. Chemical composition ( $\mathrm{g} / 100 \mathrm{~g}$ diet) and the mean energy value of the Labofeed $\mathrm{H}$ diet (Pastuszewska et al., 2000) and Se-yeast (Sel-Plex) (Rayman, 2004)

\begin{tabular}{|c|c|}
\hline Item & $\begin{array}{l}\text { Labofeed } \mathrm{H}^{2} \\
\mathrm{~g} / 100 \mathrm{~g} \text { diet }\end{array}$ \\
\hline Dry matter $^{1}$ & $88.2 \pm 0.9$ \\
\hline Protein & $21.8 \pm 1.3$ \\
\hline Lysine & 1.31 \\
\hline Methionine + cystine & 0.76 \\
\hline Tryptophan & 0.28 \\
\hline Threonine & 0.87 \\
\hline Fibre & $21.8 \pm 1.3$ \\
\hline Fat & $3.0 \pm 0.8$ \\
\hline Ash & $5.9 \pm 0.6$ \\
\hline Energy value, $\mathrm{MJ} \mathrm{ME} / \mathrm{kg}$ & 13.9 (mean from 3 samples) \\
\hline Item & High-selenized yeast (Sel-Plex) \\
\hline $\mathrm{Se}$ & $1.8 \mathrm{mg} \mathrm{Se} / \mathrm{g}$ dry yeast \\
\hline sum of identified se species & $88.3 \% \mathrm{Se}$ \\
\hline seleno-methionine & $83.0 \% \mathrm{se}$ \\
\hline seleno-cysteine & $5.0 \% \mathrm{Se}$ \\
\hline Selenite & $0.3 \% \mathrm{Se}$ \\
\hline Fatty acids ${ }^{3}$ & $\mathrm{mg} / \mathrm{g}$ dry yeast \\
\hline C16:0 & 9.0 \\
\hline cis9C16:1 & 4.1 \\
\hline C18:0 & 13.6 \\
\hline cis9C18:1 & 11.3 \\
\hline cis $11 \mathrm{C} 18: 1$ & 0.8 \\
\hline $\operatorname{cis} 9 \operatorname{cis} 12 \mathrm{C} 18: 2$ (LA) & 14.7 \\
\hline cis9cis 12cis 15C18:3 (LNA) & 0.16 \\
\hline
\end{tabular}

${ }_{1}^{1}$ ingredients: maize, wheat, oat flakes, green meal, soyabean oilmeal, fish meal, soya oil, vitamins; macroelements (Na, K, Ca and P: 3.60, 8.30, 10.68 and $7.60 \mathrm{mg} / \mathrm{g}$ Labofeed H diet, respectively) and trace elements $\left(\mathrm{Se}\right.$ as $\mathrm{Na}_{2} \mathrm{SeO}_{3}, \mathrm{Cu}, \mathrm{Zn}, \mathrm{Mn}, \mathrm{Fe}, \mathrm{Mg}: 0.63,13.9,98,112,698,1653 \mu \mathrm{g} / \mathrm{g}$ Labofeed $\mathrm{H}$ diet, respectively)

2 means from 9 samples

${ }^{3}$ main FA peaks (i.e. $\sim 95 \%$ area of all FA peak area in a GLC chromatogram

\section{Saponification and fatty acid extraction}

Spleen, pancreas and kidneys samples were frozen, lyophilized and the obtained residues were stored at $-20^{\circ} \mathrm{C}$ until saponification. Finely powdered organ samples $(\sim 50 \mathrm{mg})$ were placed in vials and treated with $2 \mathrm{ml}$ of $2 \mathrm{M} \mathrm{KOH}$ in water, $2 \mathrm{ml}$ of $1 \mathrm{M} \mathrm{KOH}$ in methanol, and $50 \mu 1$ of an internal standard (nonadecanoic acid in chloroform: $17 \mathrm{mg} / \mathrm{ml}$ ) were added. The resulting mixtures were flushed with a stream of argon (Ar) for $\sim 5$ min. Finally, the obtained solutions in tightly closed 
tubes were vigorously mixed and heated at $92-95^{\circ} \mathrm{C}$ for $10 \mathrm{~min}$, next cooled for 10 $\mathrm{min}$ at room temperature and sonicated for $\sim 10 \mathrm{~min}$. The obtained solutions were protected from the light and stored for overnight in sealed vials at room temperature under Ar. Then, $3 \mathrm{ml}$ of water were added to the hydrolysates and solutions were again vigorously vortexed. The obtained solutions were acidified with $4 \mathrm{M} \mathrm{HCl}$ to $\mathrm{pH} \mathrm{1-2} \mathrm{and} \mathrm{free} \mathrm{fatty} \mathrm{acids} \mathrm{(FAs)} \mathrm{were} \mathrm{extracted} 4$ times, each time using $3 \mathrm{ml}$ of dichloromethane (DCM). The lower DCM layer was dried with $\sim 100 \mathrm{mg} \mathrm{of}_{2} \mathrm{SO}_{4}$. To avoid loss of free FAs, extraction was repeated 4 times, each time using $3 \mathrm{ml}$ of n-heptane. Afterward, the upper n-heptane layer was combined with the DCM layer and the organic solvents were removed under a stream of Ar. The obtained residues were stored at $-20^{\circ} \mathrm{C}$ until methylation.

\section{Preparation of fatty acid methyl esters (FA-MEs)}

To residues, $2 \mathrm{ml}$ of $2 \mathrm{M} \mathrm{NaOH}$ in methanol and $50 \mu \mathrm{l}$ of BHT solution in methanol $(20 \mathrm{mg} / \mathrm{ml})$ were added while mixing, then flushed with Ar, and reacted for $1 \mathrm{~h}$ at $40^{\circ} \mathrm{C}$. After cooling, $2 \mathrm{ml}$ of $25 \% \mathrm{BF}_{3}$ in methanol were added to the reaction mixture, flushed with $\mathrm{Ar}$ and heated for $1 \mathrm{~h}$ at $40^{\circ} \mathrm{C}$. To the cooled reaction mixtures $5 \mathrm{ml}$ of water were added and then FA-MEs were extracted with $5 \mathrm{ml}$ of n-hexane. The supernatant was transferred to a vial. Separation of FA-MEs was carried out by gas liquid-chromatography (GLC), while FA-MEs containing conjugated double bonds were also re-analysed using silver-liquid chromatography ( $\mathrm{Ag}^{+}$-HPLC) with photodiode array detection (DAD) at $234 \mathrm{~nm}$ (Czauderna et al., 2003a).

\section{Analytical conditions}

The analyses of FA-MEs were performed on an Agilent $6890 \mathrm{~N}$ GC equipped with a CP7489 fused silica capillary column $(100 \mathrm{~m} \times 0.25 \mathrm{~mm}$ i.d. $\times 0.2 \mu \mathrm{m}$ film thickness; Varian, USA) and FID, while split injections were performed using an Agilent 7683 autosampler (Czauderna et al., 2005); the $\mathrm{Ag}^{+}$-HPLC equipment was as previously described (Czauderna et al., 2003a). The concentrations of all fatty acids were calculated from lyophilized spleen, pancreas and kidneys samples (i.e. dry matter).

\section{Statistical analyses}

The data are presented as means. Statistical analyses of the effects of Se or the CLA isomers in the diets were conducted using the nonparametric MannWhitney $U$ test for comparing independent experimental groups, while statistical analyses of interactions between the CLA isomer(s) and Se-yeast were performed using two-factorial ANOVA analysis (CLA isomer(s) x Se). Statistica ver. 6 and 
Microsoft Office Excel software were used in the statistical analyses (Statistica, 2002). Differences were considered significant at $\mathrm{P}<0.05$.

\section{RESULTS}

The influence of dietary Se-yeast and CLA isomers on relative body weight gain, feed intake and weight of organs

The influence of diets enriched in CLA isomer(s) and/or Se-yeast on the feed intake and the growth of rats is summarized in Table 1 . As can be seen from these results, the diet enriched in the $t 10 c 12$ isomer and Se-yeast most efficiently elevated the body weight gain (BWG) of rats and the weight of the pancreas and kidneys of rats compared with animals fed the diet supplemented with only Se-yeast as well as with the control rats. Moreover, the diet with $t 10 c 12$ and Se-yeast most effectively improved feed conversion efficiency (FCE) and tended to cause a smaller decrease in the weight of the spleen compared with the control rats (Table 1). Unexpectedly, the opposite phenomenon was observed when rats were fed the diet containing $2 \%$ of the CLA isomer mixture and when animals were fed the diet enriched in only Seyeast or one containing both the $c 9 t 11$ isomer and Se-yeast. The diet to which both c9t11 and Se-yeast were added effectively decreased the BWG of rats and showed a tendency to lower FCE, whereas the diet enriched in only $2 \%$ of the CLA isomer mixture decreased feed intake as well as tended to most effectively decrease BWG. Feeding the diet containing $2 \%$ of the CLA isomer mixture also resulted in a lower pancreas weight compared with the control and other experimental groups.

The influence of dietary CLA isomer(s) and Se-yeast on the accumulation of CLA isomers in spleen, pancreas and kidneys

Detailed chromatographic investigations showed that feeding CLA isomer(s) resulted in the efficient accumulation of CLA isomer(s) in the spleen, pancreas and kidneys of rats (Tables 3-8). In addition, increasing the dietary concentration of the CLA isomer mixture induced a significant rise in the concentration of CLA isomers $(\mathrm{P}<0.01)$ in all assayed organs. The accumulation of CLA isomer(s) in pancreas was higher than in the spleen and kidneys of rats fed diets supplemented with CLA isomer(s), regardless of the presence of Se-yeast. Interestingly, the accumulation of two isomers (i.e. $c 9 t 11$ and $t 10 c 12$ ) in the pancreas of rats fed the diets enriched to 1 or $2 \%$ of the CLA isomer mixture reduced the concentrations of other assayed fatty acids in the pancreas (Tables 4 and 7) in comparison with the concentration of these fatty acids in this organ in control rats. 


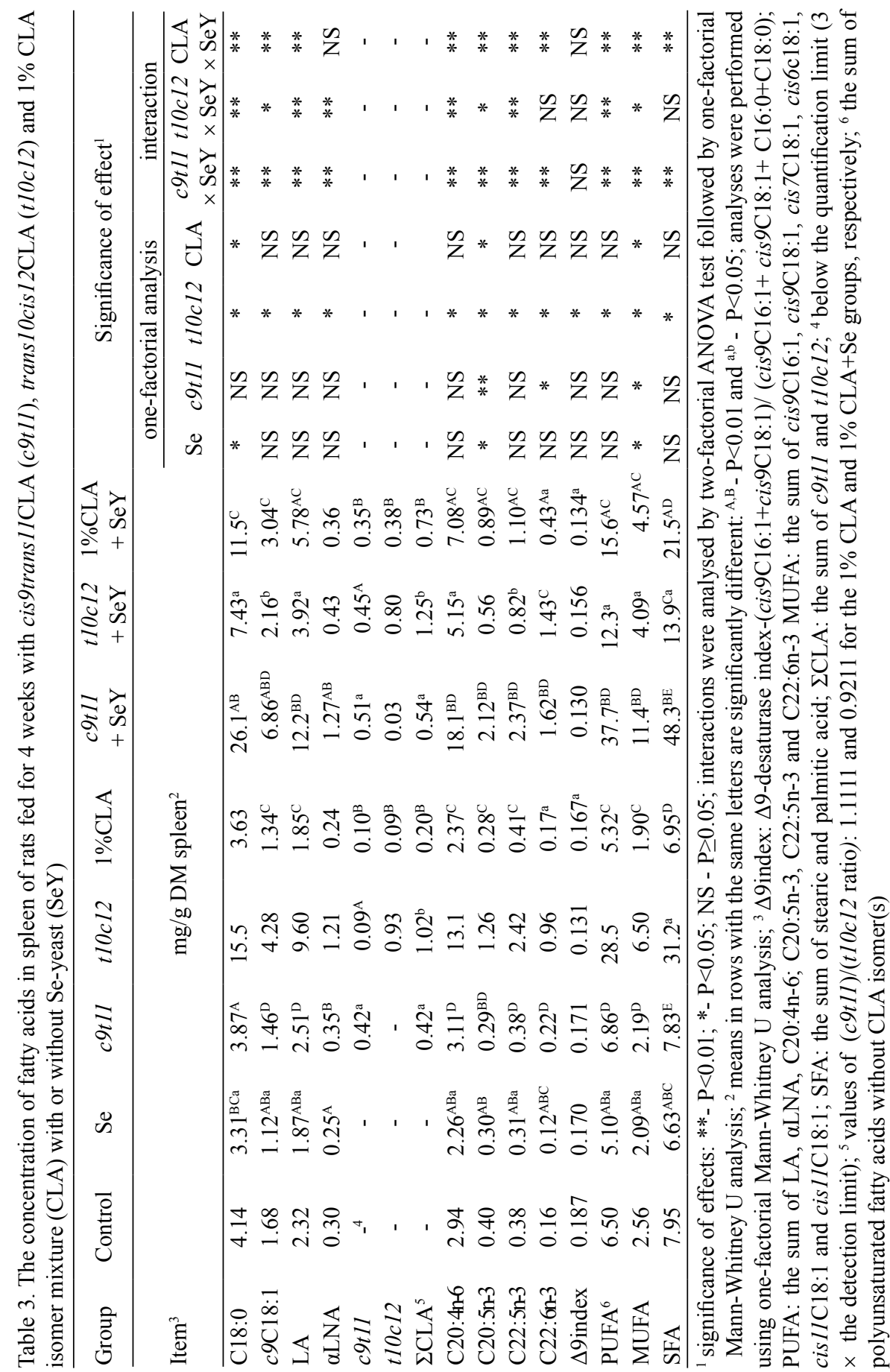




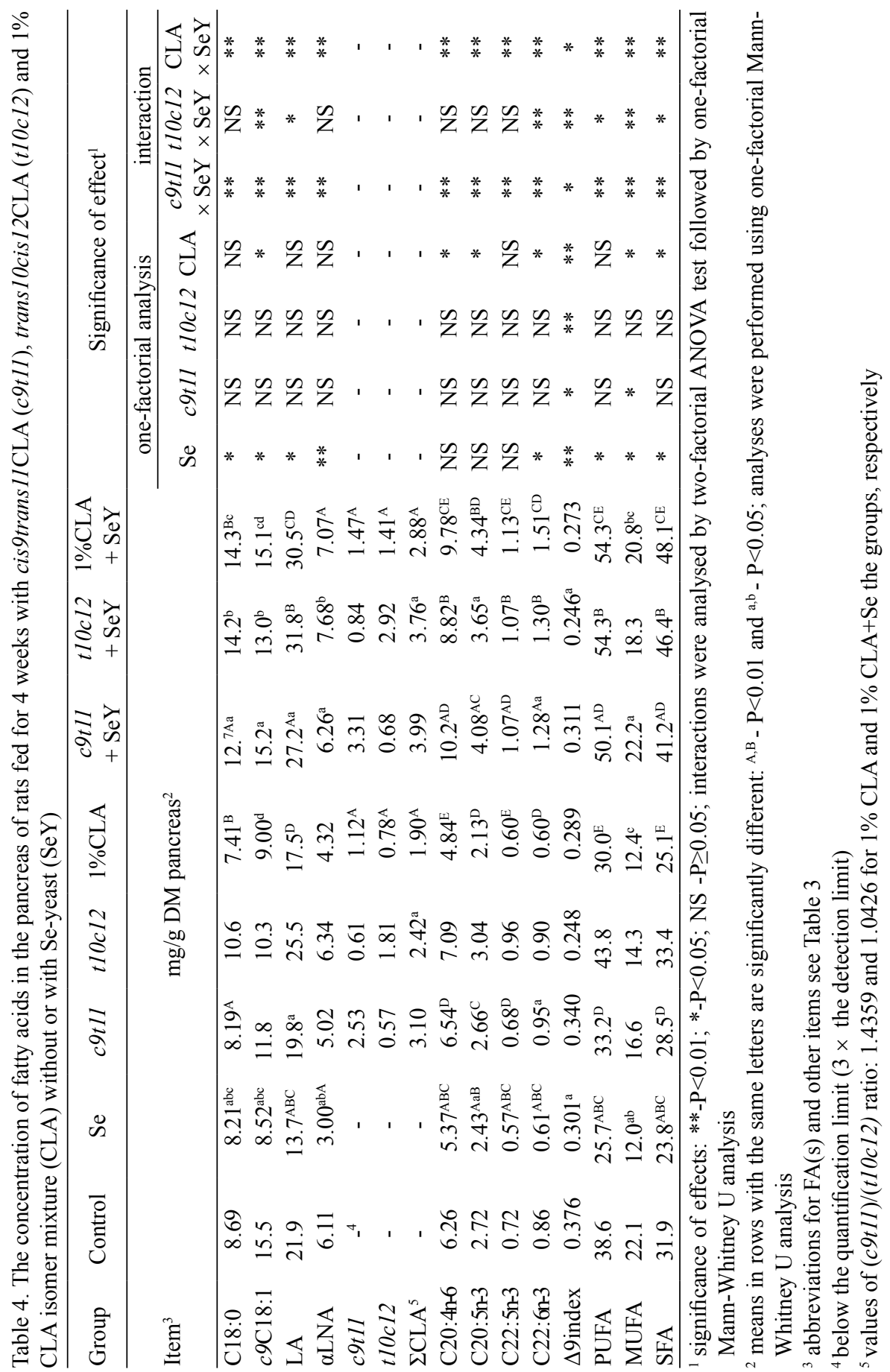




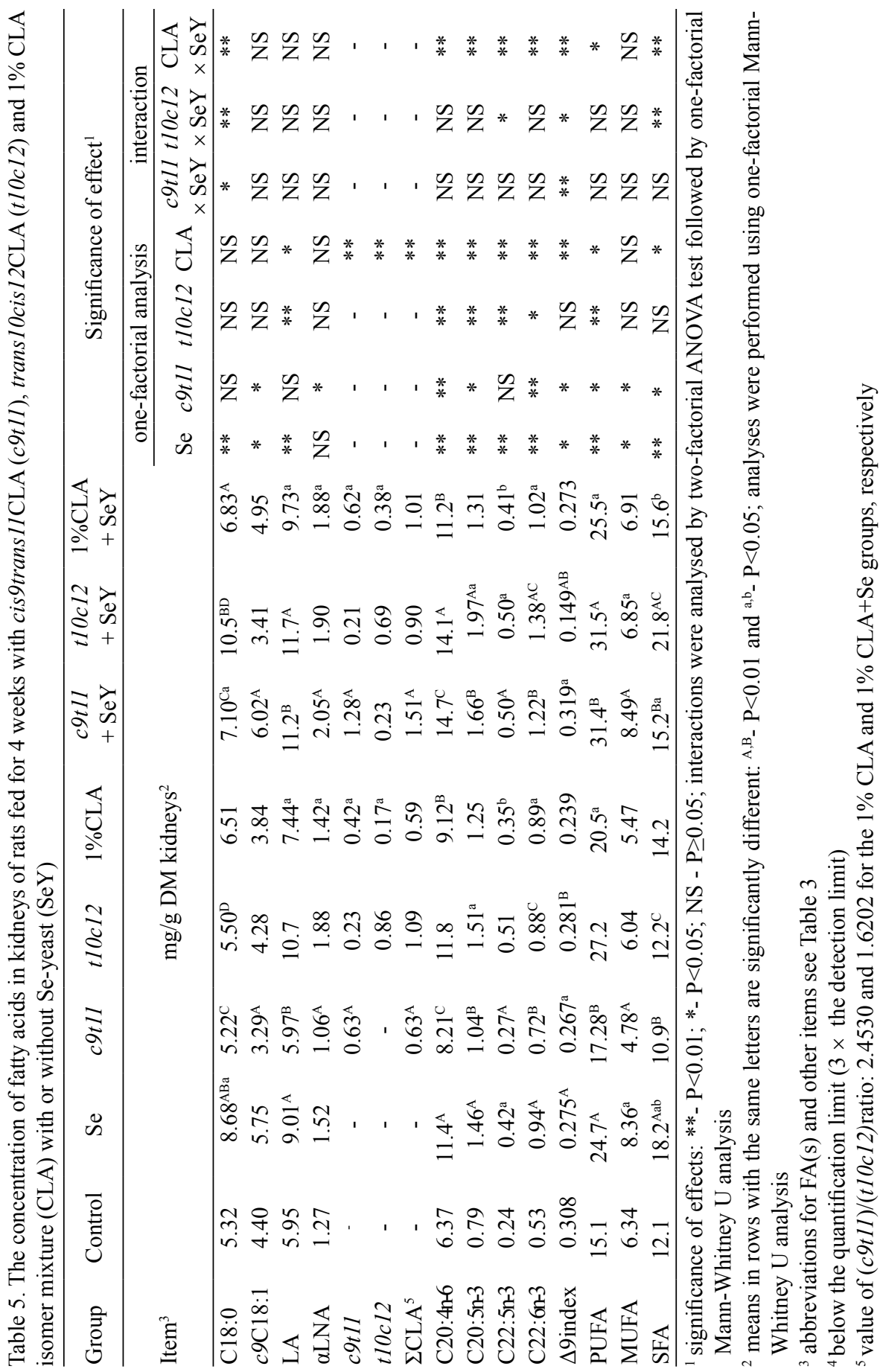


A higher concentration of $t 10 c 12$ compared with that of $c 9 t 11$ was observed in spleen of rats fed the diet containing $2 \%$ of the CLA isomer mixture regardless of the addition of Se-yeast. On the other hand, the concentration of $c 9 t 11$ was substantially higher than the concentration of $t 10 \mathrm{cl} 2$ in the pancreas and kidneys of animals fed the diets containing the CLA isomer mixture without/with Se-yeast.

Addition of Se-yeast to the diets enriched in CLA isomer(s) increased the yield of CLA isomer(s) accumulation in the spleen and pancreas in comparison with the amount of these CLA isomer(s) in spleen and pancreas of rats fed the diet enriched in only CLA isomer(s).

The addition of Se-yeast to the diets containing 1\% CLA isomers stimulated the accumulation of $c 9 t 11$ and the sum of both isomers, while tended to decrease the concentration of $t 10 c 12$ in kidneys in comparison with the amount of these isomers in kidneys of rats fed the diet enriched in only $1 \%$ the mixture of CLA isomers or t10c12, respectively. Surprisingly, the presence of Se-yeast in the diet enriched to $2 \%$ of the mixture of CLA isomers reduced the accumulation of CLA isomer(s) in kidneys compared with animals fed the diet enriched in only $2 \%$ CLA isomers.

Table 6. The concentration of fatty acids in the spleen of rats fed for 4 weeks with $2 \%$ CLA isomer mixture with or without Se-yeast

\begin{tabular}{|c|c|c|c|c|c|c|}
\hline \multirow{3}{*}{$\begin{array}{l}\text { Group } \\
\text { Item }^{3}\end{array}$} & Control & $\mathrm{Se}$ & $2 \%$ CLA & $2 \% \mathrm{CLA}+\mathrm{Se}$ & \multicolumn{2}{|c|}{ Significance of effect ${ }^{1}$} \\
\hline & \multirow{2}{*}{\multicolumn{4}{|c|}{ mg/g DM spleen ${ }^{2}$}} & \multirow{2}{*}{$2 \% \mathrm{CLA}$} & \multirow{2}{*}{$\begin{array}{c}\text { interaction } \\
2 \% \mathrm{CLA} \times \mathrm{Se}\end{array}$} \\
\hline & & & & & & \\
\hline C18:0 & 4.14 & $3.31^{\mathrm{A}}$ & 10.5 & $13.3^{\mathrm{A}}$ & $* *$ & NS \\
\hline$c 9 \mathrm{C} 18: 1$ & 1.68 & $1.12^{\mathrm{A}}$ & 3.20 & $3.53^{\mathrm{A}}$ & NS & NS \\
\hline LA & 2.32 & $1.87^{\mathrm{A}}$ & 5.89 & $7.08^{\mathrm{A}}$ & NS & NS \\
\hline$\alpha \mathrm{LNA}$ & 0.30 & $0.25^{\mathrm{A}}$ & 0.76 & $0.84^{\mathrm{A}}$ & NS & NS \\
\hline$c 9 t 11$ & -4 & - & 0.55 & 0.52 & - & - \\
\hline$t 10 c 12$ & - & - & 0.56 & 0.64 & - & - \\
\hline$\Sigma \mathrm{CLA}^{5}$ & - & - & 1.11 & 1.16 & - & - \\
\hline$C 20: 4 n-6$ & 2.94 & $2.26^{\mathrm{A}}$ & 7.55 & $10.3^{\mathrm{A}}$ & NS & NS \\
\hline$C 20: 5 n-3$ & 0.40 & $0.30^{\mathrm{A}}$ & 0.68 & $0.94^{\mathrm{A}}$ & NS & $*$ \\
\hline$C 22: 5 n-3$ & 0.38 & $0.31^{\mathrm{A}}$ & 1.11 & $1.55^{\mathrm{A}}$ & NS & NS \\
\hline$C 22: 6 n-3$ & 0.16 & $0.12^{\mathrm{A}}$ & 0.62 & $0.70^{\mathrm{A}}$ & NS & NS \\
\hline$\Delta 9$ index & 0.187 & 0.170 & 0.136 & 0.131 & NS & NS \\
\hline PUFA & 6.50 & $5.10^{\mathrm{A}}$ & 16.6 & $21.4^{\mathrm{A}}$ & NS & NS \\
\hline MUFA & 2.56 & $2.09^{\mathrm{A}}$ & 5.01 & $5.85^{\mathrm{A}}$ & $*$ & NS \\
\hline SFA & 7.95 & $6.63^{\mathrm{A}}$ & 20.4 & $25.0^{\mathrm{A}}$ & $*$ & NS \\
\hline
\end{tabular}

${ }^{1}$ significance of effects: ${ }^{* *}$ - $\mathrm{P}<0.01,{ }^{*} \mathrm{P}<0.05$; NS $-\mathrm{P} \geq 0.05$; interactions were analysed by twofactorial ANOVA test; ${ }^{2}$ means in rows with the same letters are significantly different: A,B $-\mathrm{P}<0.01 ;{ }^{\text {a,b }}-\mathrm{P}<0.05 ;{ }^{3}$ abbreviations for $\mathrm{FA}(\mathrm{s})$ and other items see Table 3

${ }^{4}$ below the quantification limit $\left(3 \times\right.$ the detection limit); ${ }^{5}$ value of $(c 9 t 11) /(t 10 c 12)$ ratio: 0.982 and 0.867 for the $2 \%$ CLA and $2 \%$ CLA + Se groups, respectively 
The current study also investigated the relationship between the percentage content of $c 9 t 11$ and $t 10 c 12$ isomers in all analysed organs of rats fed the diets enriched with a mixture of $c 9 t 11$ and $t 10 c 12$ isomers. The obtained results demonstrate that the accumulation of CLA isomers is selective and clearly show that c9t11 is preferentially accumulated in the pancreas and kidneys (Tables 4, 5, 7 and 8). Therefore, the ratio of $(c 9 t 11) /(t 10 c 12)$ in the dietary CLA isomer mixture (Table 1) was lower than the ratio of these isomers in the pancreas and kidneys of rats fed the diet enriched in the CLA isomer mixture (Tables 4, 5, 7 and 8). On the other hand, the concentration ratio of $(c 9 t 11) /(t 10 c 12)$ in the spleen of rats fed the diets enriched with the CLA isomer mixture (Tables 3 and 6) were lower in comparison with the values of this ratio in pancreas and kidneys, and similar to the concentration ratio of $(c 9 t 11) /(t 10 c 12)$ in the dietary mixture of CLA isomers (see Table 1$)$.

As can be seen from results presented in Tables 3-8, addition of Se-yeast to the diets containing the mixture of CLA isomers usually resulted in a relative increase of the percentage of $t 10 \mathrm{cl} 2$ in the spleen, pancreas and kidneys compared with these organs of rats fed the diets containing only the mixture of CLA isomers.

Table 7. The concentration of fatty acids in the pancreas of rats fed for 4 weeks with the $2 \%$ CLA isomer mixture with or without Se-yeast ${ }^{1}$

\begin{tabular}{|c|c|c|c|c|c|c|}
\hline \multirow{3}{*}{$\frac{\text { Group }}{\text { Item }^{4}}$} & Control & $\mathrm{Se}$ & $2 \% \mathrm{CLA}$ & $2 \% \mathrm{CLA}+\mathrm{Se}$ & \multicolumn{2}{|c|}{ Significance of effect ${ }^{2}$} \\
\hline & \multirow{2}{*}{\multicolumn{4}{|c|}{$\mathrm{mg} / \mathrm{g}$ DM pancreas ${ }^{3}$}} & \multirow{2}{*}{$2 \% \mathrm{CLA}$} & interaction \\
\hline & & & & & & $2 \% \mathrm{CLA} \times \mathrm{Se}$ \\
\hline C18:0 & 8.69 & $8.21^{\mathrm{a}}$ & 9.63 & $13.7^{\mathrm{a}}$ & NS & $*$ \\
\hline c9C18:1 & 15.5 & 8.52 & $7.45^{\mathrm{a}}$ & $11.3^{\mathrm{a}}$ & $* *$ & $* *$ \\
\hline LA & 21.9 & $13.7^{\mathrm{A}}$ & 19.0 & $27.5^{\mathrm{A}}$ & NS & $* *$ \\
\hline$\alpha$ LNA & 6.11 & $3.00^{\mathrm{a}}$ & 3.96 & $5.70^{\mathrm{a}}$ & NS & $* *$ \\
\hline$c 9 t 11$ & -4 & - & 2.61 & 3.65 & - & - \\
\hline$t 10 c 12$ & - & - & 1.92 & 2.73 & - & - \\
\hline$\Sigma \mathrm{CLA}^{5}$ & - & - & 4.53 & 6.38 & - & - \\
\hline$C 20: 4 n-6$ & 6.26 & $5.37^{\mathrm{A}}$ & 7.54 & $10.6^{\mathrm{A}}$ & NS & $*$ \\
\hline$C 20: 5 n-3$ & 2.72 & $2.43^{\mathrm{A}}$ & $2.72^{\mathrm{B}}$ & $4.23^{\mathrm{AB}}$ & NS & $* *$ \\
\hline$C 22: 5 n-3$ & 0.72 & $0.57^{\mathrm{A}}$ & $0.75^{\mathrm{B}}$ & $1.22^{\mathrm{AB}}$ & NS & $* *$ \\
\hline$C 22: 6 n-3$ & 0.86 & $0.61^{\mathrm{A}}$ & 1.10 & $1.42^{\mathrm{A}}$ & NS & $*$ \\
\hline$\Delta 9$ index & 0.376 & $0.301^{\mathrm{A}}$ & 0.244 & $0.238^{\mathrm{A}}$ & $* *$ & $* *$ \\
\hline PUFA & 38.6 & $25.7^{\mathrm{A}}$ & 35.1 & $50.7^{\mathrm{A}}$ & NS & $* *$ \\
\hline MUFA & 22.1 & 12.0 & $10.9^{\mathrm{a}}$ & $16.1^{\mathrm{a}}$ & $* *$ & $* *$ \\
\hline SFA & 31.9 & $23.8^{\mathrm{A}}$ & $27.5^{\mathrm{a}}$ & $42.6^{\mathrm{Aa}}$ & NS & $* *$ \\
\hline
\end{tabular}

${ }^{1}$ significance of effects: **- $\mathrm{P}<0.01 ;{ }^{*}-\mathrm{P}<0.05$, NS - $\mathrm{P} \geq 0.05$; interactions were analysed by twofactorial ANOVA test; ${ }^{2}$ means in rows with the different letters are significantly different:

A,B $-\mathrm{P}<0.01$; a,b- $\mathrm{P}<0.05 ;{ }^{3}$ abbreviations for $\mathrm{FA}(\mathrm{s})$ and other items see Table $3 ;{ }^{4}$ below the quantification limit $\left(3 \times\right.$ the detection limit); ${ }^{5}$ value of $(c 9 t 11) /(t 10 c 12)$ ratio: 1.359 and 1.337 for the $2 \%$ CLA and $2 \%$ CLA+Se groups, respectively 
Table 8 . The concentration of fatty acids in kidneys of rats fed for 4 weeks with the $2 \%$ CLA isomer mixture with or without Se-yeast ${ }^{1}$

\begin{tabular}{|c|c|c|c|c|c|c|}
\hline \multirow{3}{*}{$\begin{array}{l}\text { Group } \\
\text { Item }^{4}\end{array}$} & \multirow{3}{*}{ Control } & \multirow{3}{*}{\multicolumn{2}{|c|}{$\begin{array}{ll}\mathrm{Se} & 2 \% \text { CLA } \\
\mathrm{mg} / \mathrm{g} \text { DM kidneys } & \end{array}$}} & \multirow[t]{3}{*}{$2 \% \mathrm{CLA}+\mathrm{Se}$} & \multicolumn{2}{|c|}{ Significance of effect ${ }^{2}$} \\
\hline & & & & & \multirow{2}{*}{$2 \%$ CLA } & \multirow{2}{*}{$\frac{\text { interaction }}{2 \% \mathrm{CLA} \times \mathrm{S}}$} \\
\hline & & & & & & \\
\hline C18:0 & 5.32 & $8.68^{\mathrm{A}}$ & 10.4 & $10.5^{\mathrm{A}}$ & $* *$ & $* *$ \\
\hline c9C18:1 & 4.40 & 5.75 & 4.43 & 5.25 & NS & NS \\
\hline LA & 5.95 & $9.01^{\mathrm{A}}$ & 10.1 & $11.0^{\mathrm{A}}$ & $* *$ & NS \\
\hline$\alpha \mathrm{LNA}$ & 1.27 & 1.52 & 1.70 & 1.86 & NS & NS \\
\hline$c 9 t 11$ & - & - & 1.30 & 1.18 & - & - \\
\hline$t 10 c 12$ & - & - & 0.91 & 0.81 & - & - \\
\hline$\Sigma \mathrm{CLA}^{5}$ & - & - & $2.21^{\mathrm{a}}$ & $1.99^{\mathrm{a}}$ & - & - \\
\hline$C 20: 4 n-6$ & 6.37 & $11.4^{\mathrm{A}}$ & 12.0 & $13.2^{\mathrm{A}}$ & $* *$ & $* *$ \\
\hline C20:5n-3 & 0.79 & $1.46^{\mathrm{a}}$ & 1.58 & $1.67^{\mathrm{a}}$ & $* *$ & $* *$ \\
\hline$C 22: 5 n-3$ & 0.24 & 0.42 & 0.46 & 0.50 & $* *$ & $*$ \\
\hline C22:6n-3 & 0.53 & $0.94^{\mathrm{A}}$ & 1.20 & $1.23^{\mathrm{A}}$ & $* *$ & $*$ \\
\hline$\Delta 9$ index & 0.308 & $0.275^{\mathrm{A}}$ & 0.190 & $0.212^{\mathrm{A}}$ & $* *$ & $*$ \\
\hline PUFA & 15.1 & $24.7^{\mathrm{A}}$ & 27.0 & $29.5^{\mathrm{A}}$ & $* *$ & $*$ \\
\hline MUFA & 6.34 & 8.36 & 6.04 & 7.04 & NS & NS \\
\hline SFA & 12.1 & $18.2^{\mathrm{A}}$ & 21.0 & $21.7^{\mathrm{A}}$ & $* *$ & $* *$ \\
\hline
\end{tabular}

${ }^{1}$ significance of effects: ${ }^{*} *_{-} \mathrm{P}<0.01$; ${ }_{-} \mathrm{P}<0.05$, NS $-\mathrm{P} \geq 0.05$; interactions were analysed by twofactorial ANOVA test; ${ }^{2}$ means in rows with the different letters are significantly different: $\mathrm{A}, \mathrm{B}-\mathrm{P}<0.01$; ${ }^{\mathrm{a}, \mathrm{b}}-\mathrm{P}<0.05 ;{ }^{3}$ abbreviations for $\mathrm{FA}(\mathrm{s})$ and other items see Table $3 ;{ }^{4}$ below the quantification limit $\left(3 \times\right.$ the detection limit); ${ }^{5}$ value of $(c 9 t 11) /(t 10 c 12)$ ratio: 1.430 and 1.449 for the $2 \%$ CLA and $2 \%$ CLA+Se groups, respectively

Influence of experimental diets on the non-conjugated fatty acid constituent in rat organs

Feeding $1 \%$ of a mixture of CLA isomers or $t 10 c 12$ isomer to animals usually showed a tendency to elevate or significantly elevated the concentration of C18:0 as well as SFA in all assayed organs of rats; this effect was strongest in the spleen and weakest in the kidneys (Tables 3-5). As expected, the stimulation of accumulation of these fatty acids was usually increased in all assayed organs if the diet was enriched to a higher concentration of the CLA isomer mixture (Tables 6-8). Moreover, the addition of Se-yeast to the diets enriched in the CLA isomer mixture or $110 \mathrm{c} 12$ usually resulted in a further increase in the SFA and C18:0 concentrations in all rat organs. Consequently, the value of the $\Delta 9$-desaturase index ( $\Delta 9$ index) in all analysed organs of rats fed the diets enriched in the mixture of CLA isomers and t10c12 decreased compared with that in the organs of the control rats (Tables 3-8). The reduction of $\Delta 9$ index values was stronger if the diet was enriched in $2 \%$ the mixture of CLA isomers (Tables 3-5 vs 6-8). In addition, this effect of the CLA 
isomer mixture and $t 10 c 12$ was usually stronger in all organs if the diets with these isomer(s) were also enriched in Se-yeast. The experimental diet enriched only in Seyeast also caused a decrease in the $\Delta$ index in all organs, probably due to inhibited steaoryl-CoA desaturase mRNA expression (Tables 3-5).

On the other hand, dietary $c 9 t 11$ showed a tendency to decrease or statistically decreased the concentration of SFA as well as C18:0 in all assayed organs of rats compared with the control organs, whereas addition of Se-yeast to the diet containing $c 9 t 11$ resulted in a higher concentration of these fatty acids compared with control organs.

Our current results as well as our previous studies (Niedźwiedzka et al., 2006) have clearly shown that dietary CLA isomer(s), regardless of the addition of Se-yeast to diets, usually showed a tendency to increase or statistically increased the concentration of linoleic acid (LA) in all examined organs (Tables 3-8). The stimulating influence of the CLA isomer mixture on the accumulation of LA in these organs is stronger if the diet is enriched in a higher concentration of CLA isomers. These diets, regardless of the presence of Se-yeast, also usually tended to increase or significantly elevated the concentration of arachidonic acid (C20:4n-6) in all assayed organs. As expected, an increase in the concentration of $\mathrm{C} 20: 4 n-6$ in all organs was observed with the higher concentration of the CLA isomer mixture in the diet.

The diet containing only Se-yeast usually caused a minute influence on the concentration of $\alpha$-LNA as well as other long-chain PUFA in the organs, whereas all diets enriched in CLA isomer(s) showed mostly a tendency or statistically significant increase in the accumulation of $\alpha$-linolenic acid ( $\alpha$-LNA) in the examined organs. Moreover, the diets enriched in $t 10 c 12$ and $2 \%$ of the CLA isomer mixture, particularly those also containing Se-yeast, usually tended to increase or significantly increased the concentration of long-chain n-3 PUFA (i.e. C20:5n-3, C22:5n-3 and C22:6n-3) and the sum of polyunsaturated fatty acids (PUFA) in the organs of rats. In contrast, dietary c9t11 and the lower concentration of the administered CLA isomer mixture weakly influenced the concentrations of these fatty acids in organs, whereas the diet enriched simultaneously in $c 9 t 11$ and Se-yeast resulted in a tendency towards or statistically significant increase in the concentration of n-3 PUFA and PUFA in organs compared with the control group and rats fed the diet containing only $c 9 t 11$.

\section{DISCUSSION}

Impact of dietary Se-yeast and CLA isomers on rat growth

No macroscopic lesions or toxic symptoms caused by dietary Se-yeast and CLA isomers were observed in animals fed experimental diets. In fact, the diet 
containing $2 \mathrm{ppm}$ of Se would not be toxic for rodents (like rats or mice) because only chronic ingestion of inorganic Se compounds, selenite in particular, at a rate of more than $5 \mathrm{ppm}$ can be hepatotoxic and teratogenic in humans and animals (Tapiero et al., 2003; Tinggi, 2003). The $\mathrm{LD}_{50}$ for $\mathrm{Se}$ is about $5 \mathrm{mg} \mathrm{Se} / \mathrm{kg}$ of body mass for rats, thus, this corresponds with a diet containing $\sim 50 \mathrm{ppm}$ Se (i.e. 20 $\mathrm{g}$ of the Labofeed $\mathrm{H}$ diet enriched to $50 \mathrm{ppm}$ Se per rat per day). Furthermore, in contrast to RNA $_{\text {Se-cysteine, }}$, RNA $_{\text {Met }}$ does not discriminate between Se-Met and methionine (Met). Therefore, Se-Met is incorporated into body proteins in place of methionine (Met) (Tapiero et al., 2003). Therefore, a greater percentage of dietary Se-Met (from Se-yeast) is accumulated non-specifically into body proteins in place of Met, especially in low-Met diets. Se-Met proteins are a safe-storage form of Se in the body of laboratory animals and humans.

The current results are consistent with our earlier studies, which have also indicated that the diet enriched in the $t 10 c 12$ isomer and inorganic Se (as selenate) is the most potent in terms of elevating the body weight of rats as well as results in the best FCE (Czauderna et al., 2003b, 2004a). Moreover, our results are consistent with other earlier investigations showing that dietary CLA isomer(s) is the most potent factors in terms of antiobesity properties (Alasnier et al., 2002; Belury, 2002; Czauderna et al., 2004b). The levels of adrenaline and noradrenaline were, in fact, significantly higher in experimental animals gavaged with the CLA isomer(s). Based on our previous studies and current results we suggest that the interaction between $c 9 t 11$ and $t 10 c 12$, especially at the higher concentration of the CLA mixture, most efficiently enhances sympathetic nervous activity that leads to increased energy metabolism and eventual reduction of adipose tissue (Belury, 2002; Czauderna et al., 2003b).

The influence of dietary Se-yeast and CLA isomer(s) on the accumulation of CLA isomers in rat organs

The obtained results are consistent with our previous observations in which dietary inorganic selenium (as selenate) also increased the concentration of CLA isomers as well as other PUFA in muscles and organs of rats fed a diet enriched simultaneously in selenate and CLA isomer(s) (Czauderna et al., 2004a,b). Considering the above results, we could argue that dietary organic (as Se-yeast) and inorganic selenium protects against peroxidation of unsaturated fatty acids and, like tocopherols, provides a line of defence against reactive species, which can damage membranes and other cell structures.

The present results clearly shows that the yield CLA isomer accumulation depended upon the rat organ and geometrical configuration of the CLA isomers added to the diet. So, our current results are in agreement with the observations of 
Alasnier et al. (2002) and our previous studies on rats (Czauderna et al., 2003b, 2004a,b; Niedźwiedzka et al., 2006) showing that in the cells of the pancreas, kidneys, brain, liver, muscles and adipose tissues, $t 10 c 12$ and $t 10 t 12 \mathrm{CLA}$ isomers are more efficiently driven through $\beta$-oxidation than their 9,11 homologues. In contrast, the amount of $c 9 t 11$ and $t 10 c 12$ in the spleen of rats fed the diets enriched in the CLA isomer mixture were similar. So, the current results are in agreement with our previous observations in which the amounts of these two CLA isomers in the spleen of rats fed diets enriched in the CLA isomer mixture, irrespective of the presence of selenate, was also similar to their amount in dietary CLA isomer mixtures (Niedźwiedzka et al., 2006). The presented results suggest that in rat spleen, the rates of metabolism of dietary $c 9 t 11$ and $t 10 c 12$ are similar. However, it is also possible that the yield of $c 9 t 11$ accumulation is lower in comparison with $t 10 c 12$. This second suggestion is fully supported by the results summarized in Table 3 and our previous studies (Niedźwiedzka et al., 2006); indeed, the concentration of $c 9 t 11$ was lower than the concentration of $t 10 c 12$ in spleen of rats fed diets enriched in the same concentration of the individual isomer (i.e. $c 9 t 11$ and $t 10 c 12$, respectively; see the groups $c 9 t 11$ and $t 10 c 12$ ).

The present study clearly demonstrated that the dietary Se-yeast stimulated the accumulation of $t 10 c 12$ in the examined organs of rats. This is in good agreement with our previous studies (Czauderna et al., 2003b, 2004a,b; Niedźwiedzka et al., 2006) in which inorganic (as selenate) and organic Se-compounds (as Seyeast) also increased the percentage of $t 10 c 12$ at the expense of $c 9 t 11$. Therefore, we hypothesize that both chemical forms of dietary Se result in decreasing the capacity of $\beta$-oxidation of $t 10 c 12$ and probably also $t 10 c 12$ isomers in selected tissues and organs of rats fed diets enriched in both the mixture of CLA isomers and Se compared with animals fed feed containing only the mixture of CLA isomers.

Effect of dietary Se-yeast and CLA isomers on the concentration of non-conjugated fatty acids in rat organs

In the current study, designed specifically to investigate the influence of Se-yeast and CLA isomers, we were able to confirm our hypothesis that dietary compounds affect the concentrations of non-CLA fatty acids in all analysed organs of rats. The obtained results are consistent with our previous investigations (Czauderna et al., 2004; Korniluk et al., 2006) and other studies (Alasnier et al., 2002; Kang et al., 2004) which demonstrated that dietary $t 10 c 12$ as well as the mixture of CLA isomers were responsible for the change in the concentration of SFA and MUFA in organs and tissues of animals fed CLA isomer(s) due to decreasing the $\triangle 9$ desaturation of FAs such as C14:0, C16:0 or C18:0 (Belury, 2002; Wahle et al., 
2004). Indeed, recent studies have demonstrated that CLA isomer(s), particularly t10c12 CLA, reduce the capacity of $\Delta 9$-desaturase, inhibit steaoryl-CoA desaturase mRNA expression and fatty acid synthesis (Alasnier et al., 2002; Belury, 2002; Kang et al., 2004). Moreover, the current investigations are consistent with our previous studies (Czauderna et al., 2003b, 2004a,b; Niedźwiedzka et al., 2006), which also suggested that dietary inorganic Se (as selenate) and organic selenium (as Se-yeast) decreased the capacity of $\Delta 9$-desaturase in muscles and organs of rats.

It is well-evidenced that diets enriched in CLA isomer(s) result in changes in the concentrations of LA and LNA in the bodies of studied animals (Alasnier et al., 2002; Belury, 2002; Heird and Lapillonne, 2005). Indeed, CLA isomers as well as LA are metabolized via the same enzymatic system such as $\Delta 6$ desaturaseelongase- $\Delta 5$ desaturase. Consequently, CLA isomers compete for the same enzymes as LA (Belury, 2002; Heird and Lapillonne, 2005) and decrease the rate at which LA and its product (i.e. arachidonic acid) are metabolized. Considering the above, we suggest that the higher accumulation of LA in organs could also be due to its slower metabolism in the presence of dietary CLA isomer(s). There is also increased accumulation of arachidonic acid (C20:4n-6) in organs of rats, which may be produced by dietary CLA isomer(s), irrespective of the presence of Se-yeast (Tables 3-8). In fact, dietary CLA isomer(s) reduce arachidonatederived eicosanoids synthesis through inhibition of the constitutive enzyme, cyclooxygenase-1, and/or the inducible form, cyclooxygenase-2, at the level of mRNA, protein, or activity. CLA isomers or their elongated and desaturated products may also act as substrates or antagonist for cyclooxygenase, thereby decreasing available enzyme for arachidonate (Belury, 2002; Heird and Lapillonne, 2005).

In our study, the diets enriched in CLA isomer(s), particularly those containing Se-yeast, usually tended to or statistically increased the concentration of longchain n-3 PUFA and the sum of polyunsaturated fatty acids (PUFA) in the organs of rats. Indeed, $\alpha$-LNA is metabolized via the same desaturases and the elongase as LA (Belury, 2002). Other recent investigations (Alasnier et al., 2002; Wahle et al., 2004) also showed that a mixture of CLA isomers, or $t 10 c 12$ in particular, decreased the formation of higher metabolites of LA and LNA due to decreasing the capacity of $\Delta 6$ - and $\Delta 5$-desaturation of LA and $\alpha$-LNA in human cells. This influence of CLA isomers and especially $t 10 c 12$ is in agreement with our current and previous observations on the concentration of other polyunsaturated fatty acids in the organs of rats (Korniluk et al., 2006).

In our trial, feeding the diets enriched in $t 10 c 12$ and 2\% of a CLA isomer mixture, particularly those also containing Se-yeast, usually tended to or significantly increased the concentration of long-chain n-3 PUFA in all analysed 
organs of rats. The possible mechanism through which the accumulation of these long-chain n-3 PUFA was increased by CLA isomers, particularly $t 10 c 12$, is by the decrease in the capacity of $\Delta 6-, \Delta 4$-desaturations and elongation of these long-chain n-3 PUFA to very-long chain n-3 PUFA (Heird and Lapillonne, 2005). These dietary CLA isomers also inhibited enzymes involved in the synthesis of eicosanoids from long-chain n-3 PUFA (Heird and Lapillonne, 2005). Another reason raises the possibility that elongated and desaturated metabolites of CLA isomer(s) compete for the same enzymes as long-chain n-3 PUFA. Taken together, it seems reasonable to suggest that dietary CLA isomers, particularly $t 10 c 12$, decreased the rate of the metabolism of these fatty acids.

\section{CONCLUSIONS}

Feeding CLA isomers, irrespective of adding dietary Se-yeast, increased the concentration of these isomers in the organs of rats. In the current investigations, we could confirm our earlier suggestion that dietary Se-yeast, inorganic Se (as selenate) and CLA isomer(s) were responsible for the modification of the MUFA/ SFA ratio. Our results suggest that the mixture of $t 10 c 12$ and $c 9 t 11$, particularly $t 10 c 12$, apparently decreased the capacity of $\Delta 9-, \Delta 6-, \Delta 5$ - and $\Delta 4$-desaturation of unsaturated fatty acids in the examined organs of rats. Based on the current results and our previous studies, we suggest that the simultaneous administration of $t 10 c 12$ and Se-yeast had a beneficial influence on the growth of rats and efficiency of feed utilization. The diets enriched in CLA isomer(s), particularly together with Se-yeast, elevated the concentration of PUFA in organs. The interaction between dietary $c 9 t 11$ and Se-yeast stimulated the yield of accumulation of n-3 PUFA and PUFA in the organs of rats.

\section{REFERENCES}

Alasnier C., Berdeaux O., Chardigny J.M., Sébédio J.L., 2002. Fatty acid composition and conjugated linoleic acid content of different tissues in rats fed individual conjugated linoleic acid isomers given as triacylglycerols. J. Nutr. Biochem. 13, 337-345

Belury M.A., 2002. Dietary conjugated linoleic acids in health: Physiological effects and mechanisms of action. Annu. Rev. Nutr. 22, 505-531

Crespo A.M., Reis M.A., Lanca M.J., 1995. Effect of selenium supplementation on polyunsaturated fatty acids in rats. Biol. Tr. Elem. Res. 47, 335-341

Czauderna M., Kowalczyk J., Wąsowska I., Niedźwiedzka K.M., 2003a. Determination of conjugated linoleic acid isomers by liquid chromatography and photodiode array detection. J. Anim. Feed Sci. 12, 269-282 
Czauderna M., Kowalczyk J., Wąsowska I., Niedźwiedzka K.M., Pastuszewska B., 2003b. The effects of selenium and conjugated linoleic acid (CLA) isomers on fatty acid composition, CLA isomer content in tissues, and growth of rats. J. Anim. Feed Sci. 12, 865-881

Czauderna M., Kowalczyk J., Niedźwiedzka K.M., Wąsowska I., Pastuszewska B., 2004a. Conjugated linoleic acid (CLA) content and fatty acids composition of muscle in rats fed isomers of CLA and selenium. J. Anim. Feed Sci. 13, 183-196

Czauderna M., Kowalczyk J., Niedźwiedzka K.M., Wąsowska I., Pastuszewska B., 2004b Conjugated linoleic acid (CLA) content and fatty acids composition of muscle in rats fed isomers of CLA and selenium. J. Anim. Feed Sci. 13, 183-196

Czauderna M., Kowalczyk J., Korniluk K., Wąsowska I., 2005. Improving the analysis of fatty acids using combination of gas chromatography and $\mathrm{Ag}^{+}$liquid chromatography. J. Anim. Feed Sci. 14, Suppl. 1, 263-266

Heird W.C., Lapillonne A., 2005. The role of essential fatty acids in development. Annu. Rev. Nutr. $25,1-23$

Kang K., Miyazaki M., James M., Ntambi J.M., Pariza M.W., 2004. Evidence that the anti-obesity effect of conjugated linoleic acid is independent of effects on stearoyl-CoAdesa-turase 1 expression and enzyme activity. Biochem. Biophys. Res. Commun. 315, 532-537

Korniluk K., Czauderna M., Kowalczyk J., Mieczkowska A., Taciak M., Leng L'., 2006. Influence of dietary conjugated linoleic acid isomers and selenium on growth, feed efficiency, and liver fatty acid profile in rats. J. Anim. Feed Sci. 15, 131-146

Kornitzer M., Valente F., De Bacquer D., Neve J., De Backer G., 2004. Serum selenium and cancer mortality: a nested case-control study within an age- and sex-stratified sample of the Belgian adult population. Eur. J. Clin. Nutr. 58, 98-104

Naumanna E., Carpentier Y.A., Saebo A., Lassel T.S., Chardigny J.-M., Sebedio J.-L., Ronald P., Mensink R.P., 2006. Cis-9,trans-11 and trans-10,cis-12 conjugated linoleic acid (CLA) do not affect the plasma lipoprotein profile in moderately overweight subjects with LDL phenotype B. Atherosclerosis 188, 167-174

Niedźwiedzka K.M., Wąsowska I., Czauderna M., Kowalczyk J., Pastuszewska B., 2006. Influence of dietary conjugated linoleic acid isomers and Se on fatty acids profile in blood plasma and some tissues of rats. J. Anim. Feed Sci. 15, 471-489

Pastuszewska B., Ochtabińska A., Morawski A., 2000. A note on the nutritional adequacy of stock diets for laboratory rats and mice. J. Anim. Feed Sci. 9, 533-542

Rayman P.M., 2004. Review article. The use of high-selenium yeast to raise selenium status: how does it measure up? Brit. J. Nutr. 92, 557-573

Schomburga L., Schweizera U., Köhrle J., 2004. Visions and Reflections. Selenium and selenoproteins in mammals: extraordinary, essential, enigmatic. Cell. Mol. Life Sci. 61, 1988-1995

Statistica by StatSoft, 2002. Web: www.statsoft.pl

Suzuki K.T., 2005. Metabolomics of selenium: Se metabolites based on speciation studies. J. Health Sci. 51, 107-114

Tapiero H., Townsend D.M., Tew K.D., 2003. The antioxidant role of selenium and selenocompounds. Biomed. Pharmacother. 57, 134-144

Tinggi U., 2003. Essentiality and toxicity of selenium and its status in Australia: a review. Toxicol. Lett. 137, 103-110

Wahle K.W.J., Heys S.D., Rotondo D., 2004. Conjugated linoleic acids: are they beneficial or detrimental to health? Prog. Lipid Res. 43, 553-587

Whanger P.D., 2004. Selenium and its relationship to cancer: an update. Brit. J. Nutr. 91, 11-28 